\title{
Contribution to Solving an Inherent Problem When High Pressure Die-Casting Aluminium and its Alloys
}

\author{
Herbert Smetan \\ SMETAN Engineering GmbH, Siersburg, Germany
}

\begin{abstract}
The demands on ductility and fatigue strength of structural and chassis components are significantly higher than with other parts produced using cold-chamber-die-casting. Whereas, macroscopic oxide inclusions can be detected, classified as undesirable and removed from the production process by simple methods, the dispersed, ultrafine oxides which are more hidden are the so far underestimated source of extensive damage with regard to the ductility and fatigue strength of components produced in high-pressure-die-casting. Assuming that future applications of die-cast-components will increase demands even further, the author proposes an ultimate approach to solving these inherent problems by transferring experience from proven systems in the field of low-pressure-die-casting towards high-pressure-die-casting. In the currently dominating derivatives of the high-pressure die-casting method used for aluminium and its alloys, a great deal of effort is made to compensate for the symptoms of the more or less inherent disadvantages of very fast filling of the mould cavity. Basically, however, it must be assumed that most of the dispersed oxide-films are formed already at the stage of filling the aluminium into the shot-sleeve. This has led to a search for solutions in which the shot-sleeve is filled from below independent of evacuation of the mould cavity. As a result, various comparative studies have shown that components made by filling the mould cavity from below, combined with stronger evacuation of the cavity, produced the lowest amount of fine porosity in heat-treated parts. The author is convinced that the proposed concept of bottom-filling the slot sleeve under inert-gas-protection is ideally suited to producing high standard components of exceptional metallurgical quality. Combined with proven vacuum technology, die tempering and water-free spraying methods, it should ultimately be possible to achieve exceptionally high component properties.
\end{abstract}

Key words: Cast structural components, inherent limitations of HPDC, impact of oxide films on fatigue strength, creation of dispersed oxide films, concept for bottom-filling the slot sleeve.

\section{Introduction}

Independent of the ultimately successful solutions towards future power train systems in private cars, the manufacturers of construction elements made of aluminium die-castings which may in future dominate the field in light-weight bodywork and chassis parts still find themselves facing new challenges.

The demands on ductility and fatigue strength of structural and chassis components are significantly higher than with other parts produced using cold-chamber die-casting. At the same time, inherent die-casting problems are accepted both by the traditional manufacturer and by the experienced user

Corresponding author: Herbert Smetan, Dipl. -Ing, research fields: material and foundry science and technology, manufacturing engineering. of these components, full in the knowledge that the potential available in the various aluminium foundry alloys is not exploited in real components. Also, there is a wide scatter in fracture strength, yield strength, elongation and fatigue strength values i.e. values which ultimately determine process capability are locally very different and usually extremely low. Even if the designer is able to compensate, by applying additional safety margins in dimensioning, it is not difficult for competitive materials and methods to offset the potential weight advantage offered by aluminium. In particular in the case of casting methods, it should be questioned as to what ultimately should be considered as the inherent limitations. The author attempts here to do just that, both from the practical stand point by examining the metallurgical 
aspects of aluminium foundry alloys and the material requirements of a casting process.

\section{Starting Point}

Since 1971, the author has been engaged in various positions and capacities as foundry and materials specialist for suppliers of the global automotive industry, including almost two decades leading an international group of aluminium foundries which specialise exclusively in the production of cylinder heads and crankcases. In that period the basic question was how it came about that, since the earliest days of casting aluminium foundry alloys, it could be accepted that the mechanical properties exhibited by components remained significantly behind the actual potential of these extremely capable but also expensive materials, and that the values always exhibited considerable scatter. Often, the more demanding the alloy in question, the greater is the discrepancy between the values obtained and those that could be reached -for which reason hardly any differences can be found in actual components. This situation is reflected in the related standards and data sheets. In contrast to ferrous casting materials, this results in the users applying safety margins that cannot be justified in any way for such a modern, light weight construction material as aluminium and, consequently, limits its wider use to a considerable degree.

Essentially, the following points must be taken into consideration:

- In pure aluminium the shrinkage in volume during solidification is $7 \%$ and in its alloys between 2.5 and $7 \%$. On the other hand in ferrous alloys, depending on the carbon content and graphite formation, this amounts to only $0.6-3.2 \%$.

- In ferrous materials, because the density is three times higher, the effective pressure at the interface which promotes infiltration of residual melt into the crystallising structure is significantly higher than that of the aluminium foundry alloys.
- The tendency to form more tenacious oxide skins and oxide films, which often become dispersed throughout the casting as folded bundles representing detrimental interfaces in the structure. This is very pronounced in aluminium foundry alloys and with few exceptions other materials containing aluminium as an additive - unique in industrial casting.

- Another defect specific to aluminium is the tendency for molten aluminium to take up hydrogen and to precipitate this out during solidification mainly in the form of finely dispersed spherical, gaseous porosity at the grain boundaries and interfaces of the eutectic phases.

The present day aluminium foundry alloys are trusted to exhibit significant reserves in properties to enable them to be used for an ever increasing range of new products. This in turn places significantly increased material-specific demands on these components. Without question, successive, step-by-step improvements both in the alloys themselves and in the processing have enabled improvements to be achieved, but these are asymptotically approaching a process-specific limit. Basically, because of their notch-like behaviour, non-metallic discontinuities and material heterogeneity have a very decisive influence on properties under mechanical and thermal fatigue load conditions. In that respect the dispersed oxide impurities in the matrix of a component are extremely detrimental. Any, even the briefest, interruption of the oxide skin on molten aluminium during the complex mould-filling process results in extremely thin oxide films which become incorporated in the cast structure as folded bundles and usually have an extremely negative effect on the mechanical properties (Fig. 1) [1].

It is important to differentiate here, on the one hand, between slowly growing oxide skins that form mainly on the surface of aluminium melts in melting or holding furnaces and can be incorporated in the component as a result carelessness and, on the other hand, oxide skins that form during the mould filling 


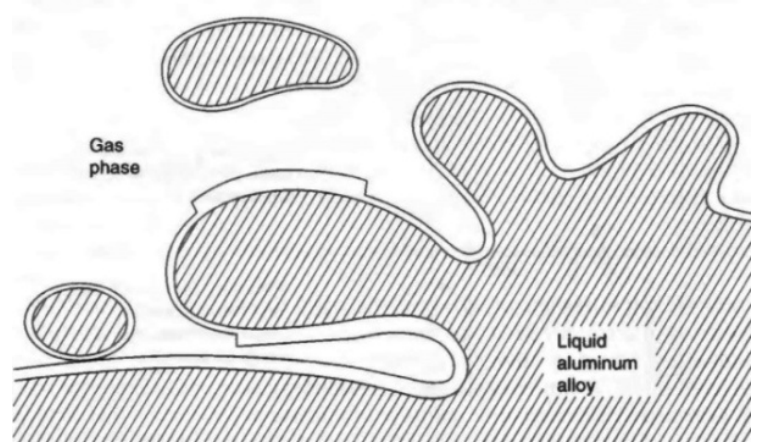

(a)

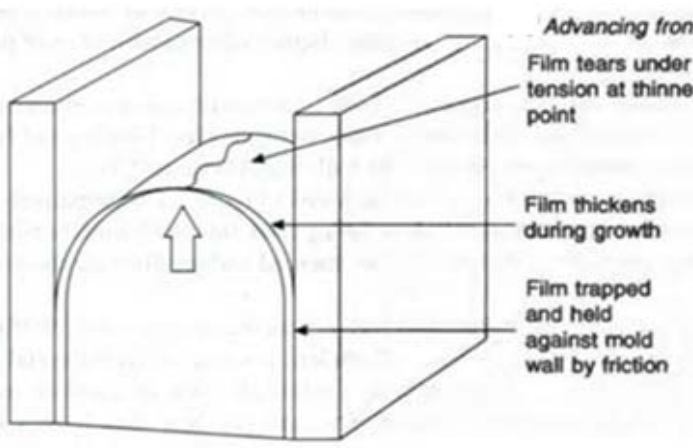

(b)
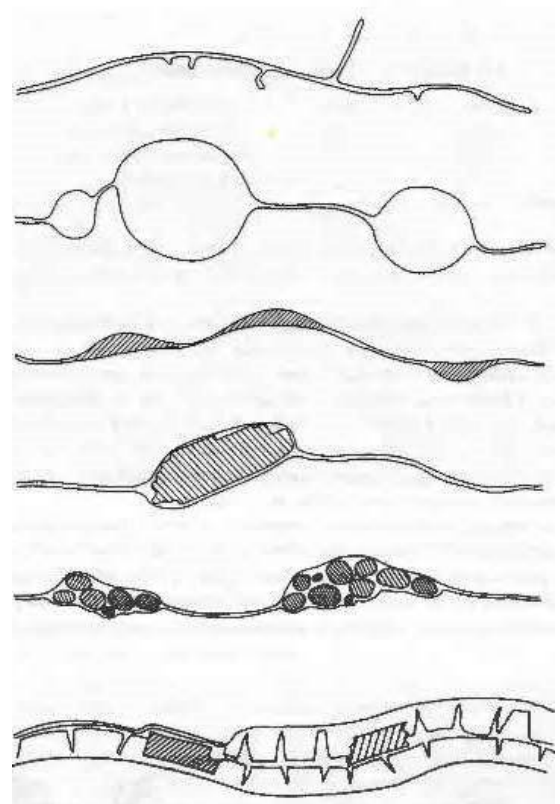

(d)

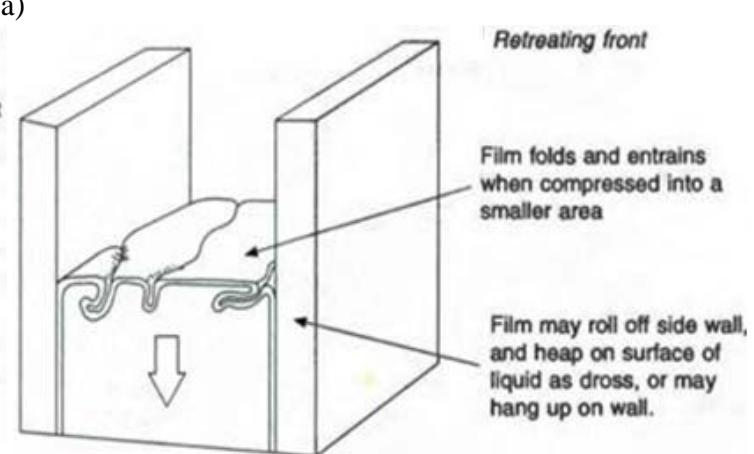

(c)

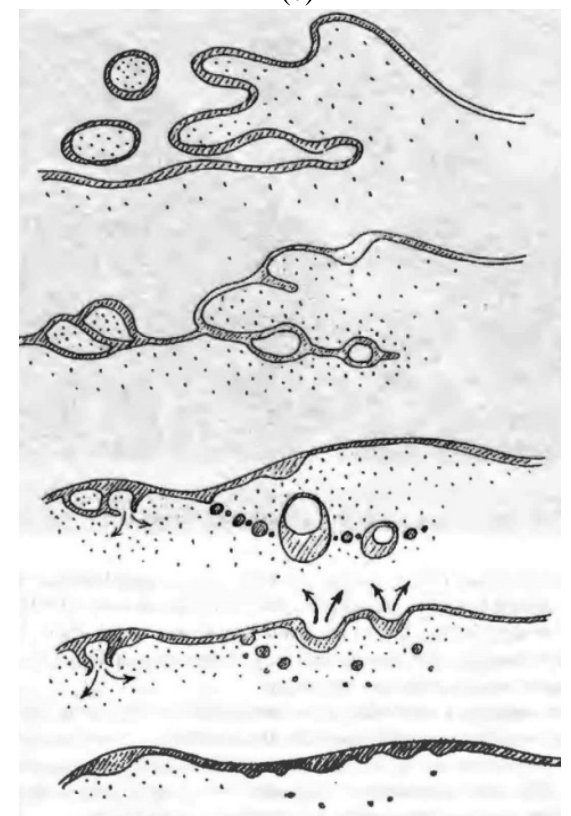

(e)

Fig. 1 Principles of oxide formation on the surfaces of liquid aluminum alloys exposed to oxygen containing gases [1], (b) and (c) oxide formation during uncontrolled filling of the mould [1], (d) and (e) occlusion of oxide and air during uncontrolled filling of the mould [1].

process. The first type forms usually clusters of oxide which are easy to recognise in the microstructure and are usually conspicuous during crack detection. The oxide formed during mould filling on the other hand can become dispersed during that process and are not detected using classical destructive or non-destructive testing - also not even by means of sophisticated metallographic methods of investigation. These dispersed oxide films are hardly visible even to the trained eye and can at best be detected using the 
electron microscope.

Whereas, macroscopic oxide inclusions can be detected, classified as undesirable and removed from the production process, the dispersed, ultrafine oxides which are more hidden are the source of extensive damage. In the distant past, and repeatedly since then, the author showed interest in the service life of cutting tools employed for machining aluminium wheels produced using low pressure die-casting and, as a rule, excellent mould filling. Thereby, the cutting tool used to machine wheels that had been cast from metal melted in a medium frequency induction furnace exhibited at most only a tenth of the service life of those tools machining wheels from metal that had been melted in a resistance heated crucible furnace. The effect responsible for that was the same as with the filling of the mould viz., the intensive movement of the metal in the induction furnace breaks up the oxide films on the surface of the melt and stirs in the continuously, newly forming oxide films. As a result, due to their very similar density, these oxide films become dispersed throughout the molten metal and cannot not be removed by the normal purification processes used by die-casting foundries. This meant that the trump card of aluminium viz., its ability to provide protection against corrosion thanks to an impermeable oxide layer, became its Achilles' heel when processed in the molten state.

Regardless of the nature of a discontinuity or heterogeneity in the structure of an actual component, their effect is defined basically by factors of shape, length and size as well as inherent strength in relation to the parent metal. In the case of alternating thermal stresses, the difference in coefficients of thermal expansion will also play a role.

Also the specific thermal conductivity of the material will have an additional effect on the resistance to thermal shock, because this causes a change in the temperature gradient (this is mentioned here only for sake of completeness). In this respect the characteristic values for dynamic loading react much more to discontinuities than do the values for straightforward static loading. And, it is exactly these dynamic loading values that are relevant for construction design purposes. Basically, it should be assumed that the strength of a material is usually influenced more by its discontinuities than by the characteristics of its matrix, for which reason it is not helpful to introduce new alloys as long as we are far from being able to exploit the potential of the existing alloys. Even though attempts are made for various applications to compensate for the inherent disadvantages via high purity alloys, that should be viewed simply for reasons of cost only as an emergency solution.

In the past the author has always taken samples from continuously casting ingots to illustrate the potential of an aluminium foundry alloy with respect to conventional values i.e. fracture strength, yield strength, elongation and flexural fatigue strength, in each case in comparison with the values used to compare industrial casting methods. Admittedly this is a demanding comparison and is stricter than the more comparative measurement of a quality index normally used to judge casting methods. Separately cast test bars, still widely used for reference purposes, should in the author's opinion, be employed only to compare the quality of a melt. These measurements have, therefore, nothing to do with real components, the properties of which are mostly influenced by process effects.

Continuously cast ingots exhibit not only an optimally solidified, uniform structure, but also the ideal case with respect to inclusion of non-metallic impurities. For that reason, when continuously casting foil stock ingots, the oxide particles in the launder are frequently measured in real time using the LIMCA $\mathrm{CM}^{\circledR}$-Method (Liquid Metal Cleanliness Analyzer) by $A B B$ [2], to achieve a melt free of dispersed oxides. With similar goals in mind, the PoDFA ${ }^{\circledR}$-Method (Inclusion Identification and Quantification Analysis) from ABB [2] is used in leading jobbing foundries for 
quantitative assessment of oxide fines in melts. By re-melting components, the so called Cold PoDFA ${ }^{\circledR}$-Method can also be used to judge the quality of components by assessing the amount of fine, dispersed oxide present. The fact that this method is hardly ever used in foundries can be taken as an indication of the low priority granted to the detection of fine oxide inclusions in industrial practice.

Samples from actual components, produced using a dynamic tilt casting method, were taken and used to measure static strength values at room temperature and fatigue strength values at $150{ }^{\circ} \mathrm{C}$ using various aluminium foundry alloys in different heat treated conditions (Table 1 and Fig. 2). Due to their exemplary, low content of dispersed oxide films, the values obtained significantly exceeded the values regarded today as benchmarks for these alloys. The principles involved here are described in detail by the author elsewhere [3, 4] and in SMETAN engineering Innovations Volume 1.

In die-casting, provided they are not dragged in with the molten aluminium, these dispersed oxide films are created during the actual mould filling, especially during ladling. Even if the gating system for gravity die-casting is designed according to the parameters proposed by Friedrich Nielsen [5], oxide films can be dispersed in particular by turbulence in the pouring basin or at changes in direction at the sprue - runner transition and thereafter. However, also in the interior of the mould cavity, complex flow patterns cause oxide films to be formed and stirred into the molten metal [1]. In dynamic tilt casting, freshly formed oxide films can be dispersed if the molten metal is poured indiscriminately from a ladle into the casting basin (Fig. 3).When this happens, these oxide films become uniformly dispersed throughout the component. This means that, if a melt is already highly contaminated with fine, dispersed oxide films in the casting basin, the significance of the actual mould filling process is in fact less because, as has been demonstrated in trials by the author, the disadvantageous effect on the values of the material in question increases exponentially already from an extremely low concentration of such oxide particles.

Table 1 Strength values after various heat-treatments, obtained with actual components made from different aluminium casting alloys using dynamic tilt-casting.

\begin{tabular}{|c|c|c|c|c|c|c|c|c|c|c|}
\hline \multirow{3}{*}{\multicolumn{2}{|c|}{$\begin{array}{l}\text { Mechanical properties } \mathrm{c} \\
\text { At room temperature } \\
\mathrm{d}_{0}=5.0 \mathrm{~mm} \\
\mathrm{~L}_{\mathrm{t}}=51.0 \mathrm{~mm}\end{array}$}} & \multicolumn{3}{|c|}{ AC-AlSi10MgCu } & \multicolumn{3}{|c|}{ AC-AlSi6Cu4 } & \multicolumn{3}{|c|}{ AC-AlSi7Cu3 } \\
\hline & & \multirow{2}{*}{$\frac{\mathrm{R}_{\mathrm{PO} .2}}{\mathrm{MPa}}$} & \multirow{2}{*}{$\frac{\mathrm{R}_{\mathrm{m}}}{\mathrm{MPa}}$} & \multirow{2}{*}{$\begin{array}{l}A_{5} \\
\%\end{array}$} & \multirow{2}{*}{$\frac{\mathrm{R}_{\mathrm{PO} .2}}{\mathrm{MPa}}$} & \multirow{2}{*}{$\begin{array}{l}\mathrm{R}_{\mathrm{m}} \\
\mathrm{MPa}\end{array}$} & \multirow{2}{*}{$\begin{array}{l}A_{5} \\
\%\end{array}$} & \multirow{2}{*}{$\frac{\mathrm{R}_{\mathrm{PO} .2}}{\mathrm{MPa}}$} & \multirow{2}{*}{$\begin{array}{l}\mathrm{R}_{\mathrm{m}} \\
\mathrm{MPa}\end{array}$} & \multirow{2}{*}{$\begin{array}{l}\mathrm{A}_{5} \\
\% \\
\end{array}$} \\
\hline & & & & & & & & & & \\
\hline \multirow{4}{*}{ As cast } & Average & 98 & 195 & 9.8 & 153 & 235 & 3.0 & 169 & 242 & 2.5 \\
\hline & Conbustion chamber & 101 & 192 & 8.4 & 163 & 239 & 2.8 & 178 & 249 & 2.5 \\
\hline & Struts inbetween & 92 & 197 & 12.0 & 143 & 239 & 3.3 & 161 & 243 & 2.8 \\
\hline & Joint-face & 101 & 197 & 9.0 & 153 & 226 & 3.0 & 168 & 233 & 2.2 \\
\hline \multirow{4}{*}{ T6W } & Average & 277 & 334 & 4.0 & 357 & 383 & 2.3 & 304 & 353 & 2.2 \\
\hline & Conbustion chamber & 272 & 326 & 4.4 & 347 & 384 & 2.2 & 299 & 351 & 1.0 \\
\hline & Struts inbetween & 280 & 345 & 4.0 & 393 & 393 & 2.7 & 312 & 366 & 2.6 \\
\hline & Joint-face & 278 & 331 & 3.5 & 332 & 371 & 2.1 & 302 & 343 & 2.1 \\
\hline \multirow{4}{*}{ T6A } & Average & 190 & 263 & 5.2 & 259 & 321 & 2.5 & 233 & 290 & 2.6 \\
\hline & Conbustion chamber & 194 & 264 & 5.0 & 263 & 327 & 2.7 & 233 & 300 & 2.4 \\
\hline & Struts inbetween & 189 & 266 & 6.0 & 266 & 322 & 2.4 & 239 & 293 & 2.4 \\
\hline & Joint-face & 187 & 259 & 4.5 & 248 & 314 & 2.3 & 227 & 276 & 2.9 \\
\hline \multirow{4}{*}{ T7A } & Average & 165 & 229 & 6.0 & 218 & 305 & 3.3 & 232 & 300 & 2.3 \\
\hline & Conbustion chamber & 168 & 229 & 5.5 & 222 & 312 & 3.5 & 234 & 306 & 2.5 \\
\hline & Struts inbetween & 166 & 233 & 6.5 & 224 & 311 & 3.2 & 241 & 307 & 2.1 \\
\hline & Joint-face & 161 & 225 & 6.0 & 209 & 293 & 3.3 & 220 & 286 & 2.2 \\
\hline
\end{tabular}




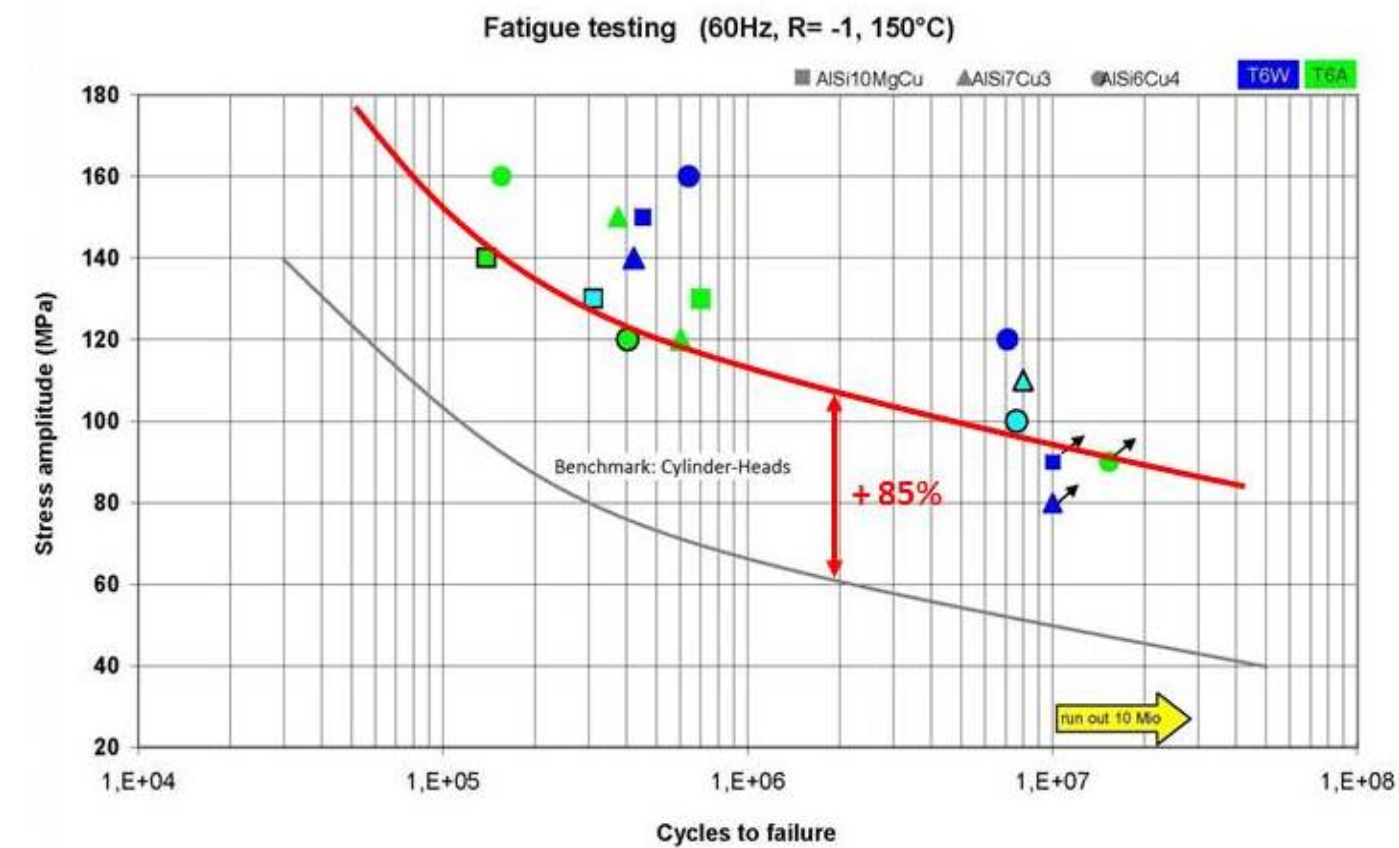

Fig. 2 Fatigue strength values at elevated temperature obtained from actual cylinder heads in various aluminium casting alloys produced using a new tilt-casting method in comparison with conventional component values.

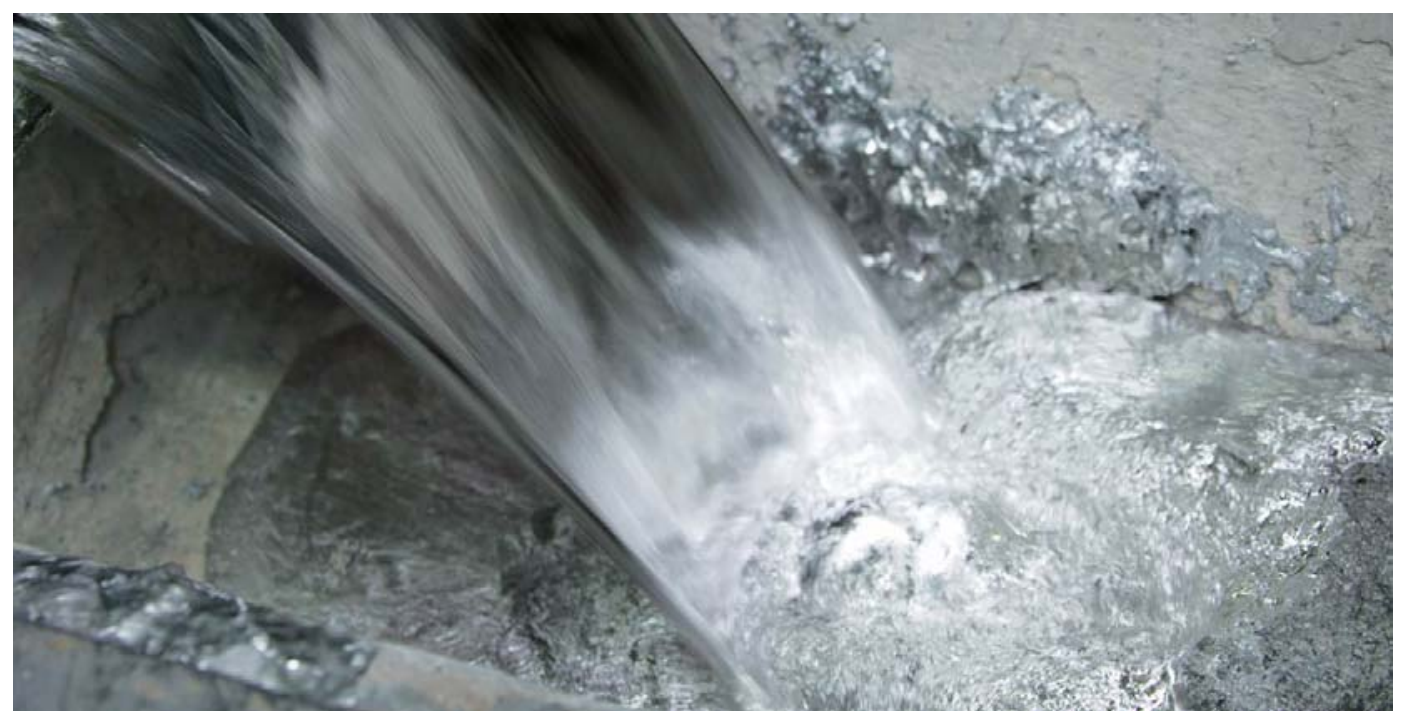

Fig. 3 Any interruption of the protective oxide skins on molten aluminium results in newly built, extremely thin oxide films.

If such grave differences, in particular in fatigue strength and ductility, arise in gravity die-casting components due to process-specific differences in dispersed oxide films simply as a result of different gating systems, all the more must be their effect in pressure die-casting. In general the fatigue strength and ductility values obtained by high pressure die-casting lie significantly lower than those obtained by gravity die-casting and take advantage, therefore, to a much smaller degree of the potential in the corresponding aluminium foundry alloys.

\section{Specific Starting Points}

In the currently dominating derivatives of the pressure die-casting method used for aluminium and its alloys (Fig. 4), a great deal of effort is made to compensate for the symptoms of the more or less inherent disadvantages of very fast filling of the mould cavity. 


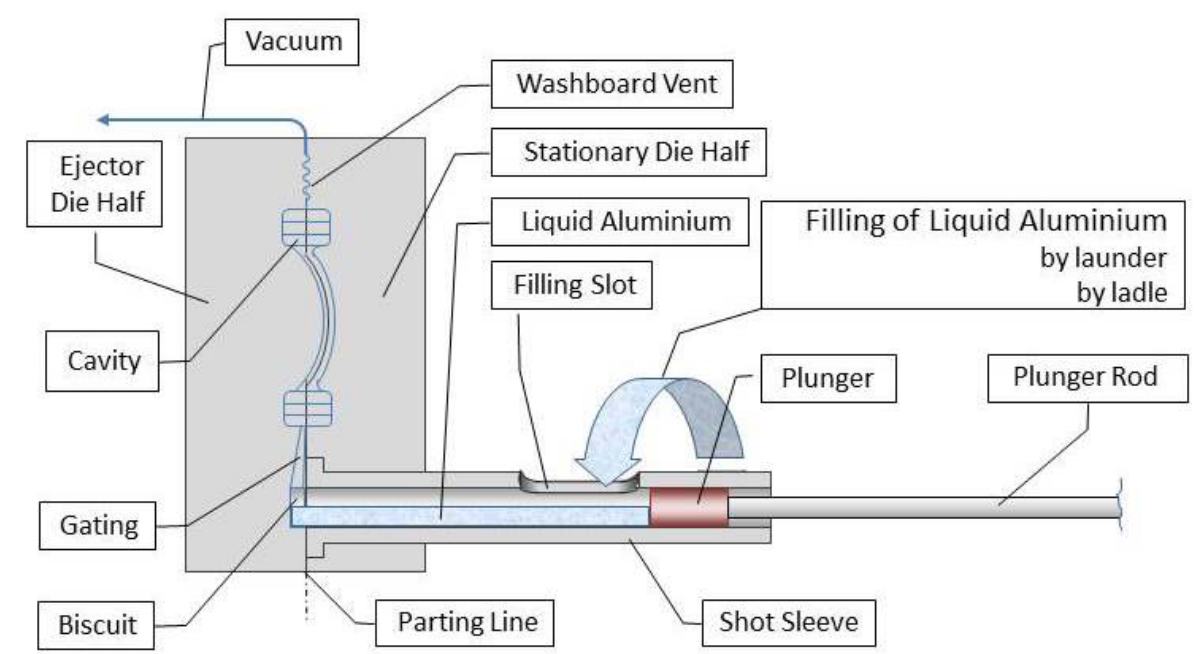

Fig. 4 Schematic representation of a die-casting unit with mould on a cold chamber die-casting machine for aluminium foundry alloys.

Table 2 Residual oxygen content in mould cavities as a function of different levels of vacuum, with and without flushing with nitrogen.

\begin{tabular}{llllllllllll}
\hline Residual oxygen content in mould cavities as a function of different levels of vacuum (with and without flushing with nitrogen) \\
\cline { 2 - 13 } Evacuation level of mould cavity & $0 \%$ & $10 \%$ & $20 \%$ & $30 \%$ & $40 \%$ & $50 \%$ & $60 \%$ & $70 \%$ & $80 \%$ & $90 \%$ & $100 \%$ \\
\hline $\mathrm{O}_{2}$ without $\mathrm{N}_{2}$-flushing & $21 \%$ & $19 \%$ & $17 \%$ & $15 \%$ & $13 \%$ & $11 \%$ & $8 \%$ & $6 \%$ & $4 \%$ & $2 \%$ & $0 \%$ \\
$\mathrm{O}_{2}$ with $\mathrm{N}_{2}$-flushing & $0 \%$ & $0 \%$ & $0 \%$ & $0 \%$ & $0 \%$ & $0 \%$ & $0 \%$ & $0 \%$ & $0 \%$ & $0 \%$ & $0 \%$ \\
\hline
\end{tabular}

In this connection customised standard electronic real-time controls are employed to exercise a positive influence on the millisecond filling of the mould cavity.

Also, using the simulation methods available today, this filling process is optimised in such a way that both the gating system and the systems forventingthe cavity are designed and positioned in the best possible manner.

Further, the mould cavity is very often connected to a vacuum system and, depending on the air-tightness, a larger or smaller negative pressure is formed before the actual filling of the cavity. As the possible negative pressure is, however, still far from a technical vacuum, it can be assumed that the residual oxygen in the cavity is sufficient to allow oxides to be formed almost unhindered. Experience in vacuum metallurgy supports this. The negative pressure created reduces only the volume of gases trapped by the turbulent filling process (Table 2).

Basically, however, it must be assumed that most of the dispersed oxide films are formed already at the stage of filling the aluminium into the shot sleeve (Fig. 5). This filling is normally carried out using a ladle or launder exposed to the open air and, in traditional die-casting with the exception of the accuracy of the quantity of metal fed to the shot sleeve, is given little attention although it is an essential step in the casting process. Further, it is seldom that water and oil-based lubricant or separating liquids are used sparingly at that stage, with the result that - besides a dispersion of oxides - a considerable amount of hydrogen is absorbed and amorphous carbon is dispersed too (Fig. 6). For that reason, the focus of the proposal made by the author lies especially on this first process step.

\section{Proposal for Avoiding Dispersed Oxide Films in Aluminium Pressure Die-Casting}

In the past various proposals have been made to reduce or eliminate this urgent problem by optimising the feed of metal into the shot sleeve from above, or by filling the shot sleeve from below. Whereas even 


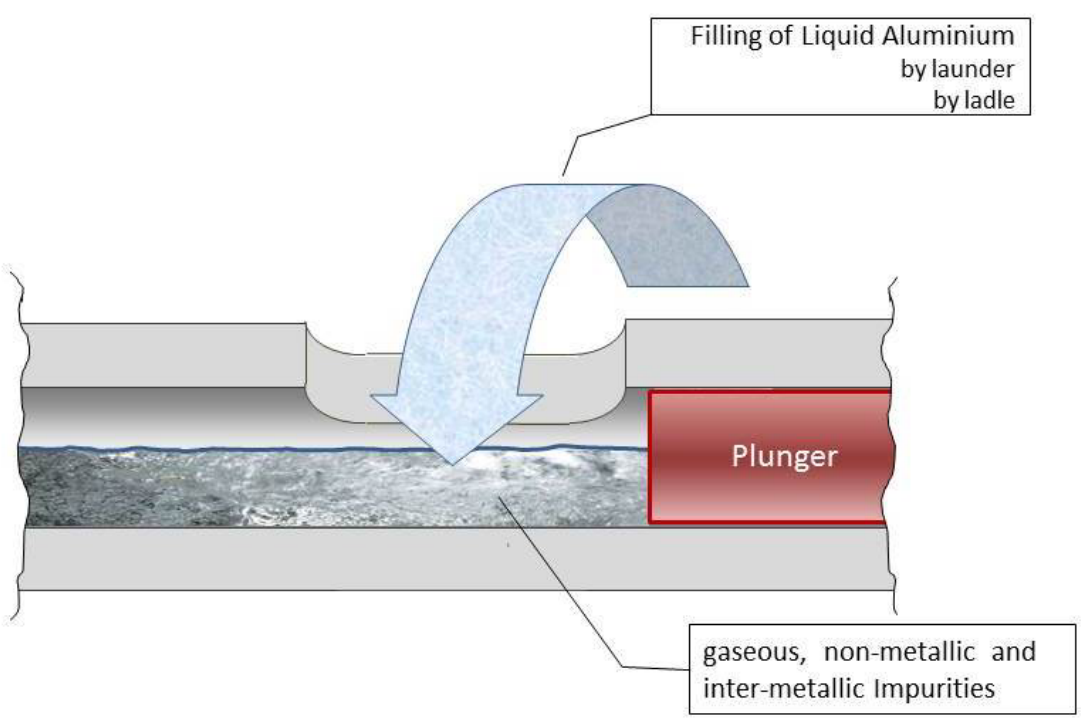

Fig. 5 Schematic representation of the filling of molten aluminium alloys into the shot sleeve of a cold chamber die-casting machine.

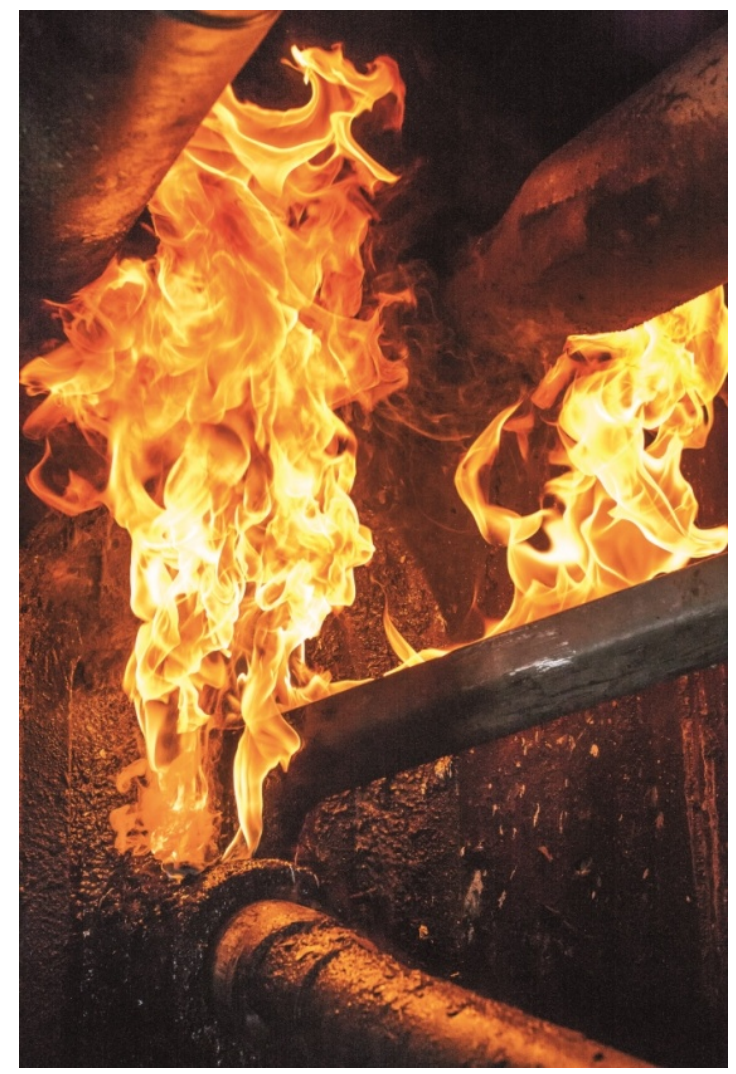

Fig. 6 Example for careless filling of the slot sleeve.

coverage with a protective gas during optimised, low-turbulence feed of metal from above is able to solve the problem of oxide formation only to a limited degree, the filling from below by means of a feed tube very often raises concerns from the point of machine design. The author feels, however, that these approaches could at least point to a method that is in the interest of all die-casters producing ductile or mechanically highly stressed components with a certain amount of safety relevance. Various solutions to filling the shot sleeve from below using a feed tube can be found for conventional cold chamber die-casting methods and for vertical squeeze casting machines in the relevant technical literature. To date no other solution of significant industrial consequence exists except the company-specific Vacural-Process $\AA$, developed and patented by Müller Weingarten (now Oskar Frech GmbH) and VAW Aluminium AG (now Aleris) [6]. In the Vacural-Process ${ }^{\circledR}$, the evacuation of the cavity and the shot sleeve is maintained throughout the whole of the filling process.

As a result of this vacuum, the required amount of metal is sucked via a feed tube out of the holding furnace into the shot sleeve, and the air in the cavity as well as the gases arising due to contact between the melt and separating fluids with the cavity wall are drawn off (Fig. 7). The amount of gases trapped in castings made using this method is only a fraction of that experienced with conventionally cast parts. Also the smaller amount of pre-solidification in the shot sleeve can be regarded as quality relevant. 


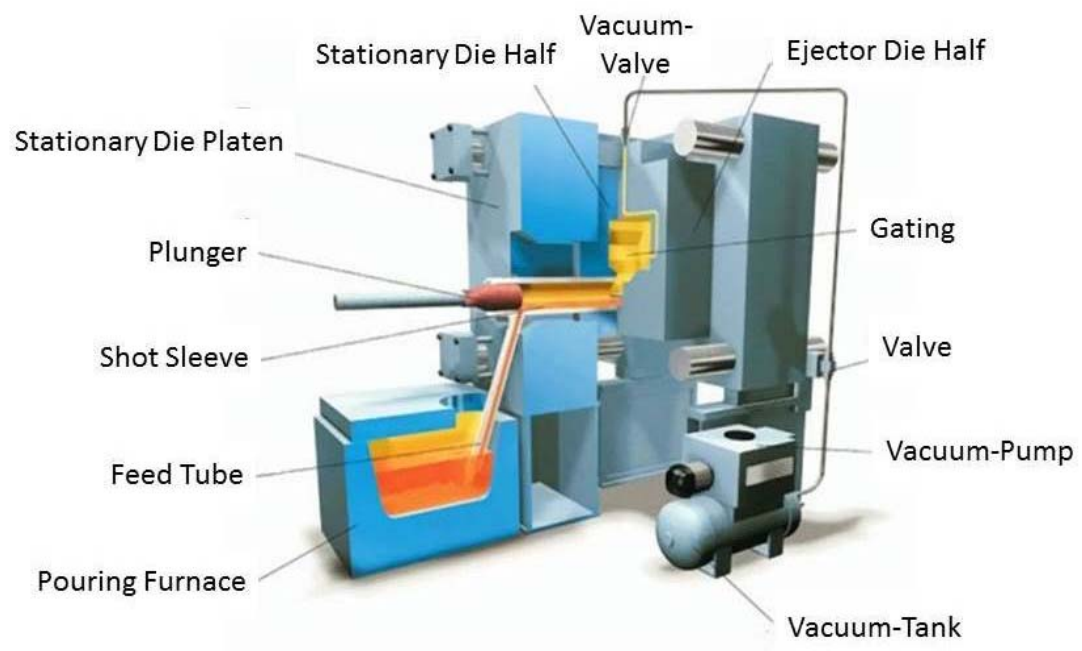

Fig. 7 Principle of the Vacural-Process ${ }^{\circledR}[6]$.

On the one hand, however, filling from below via a feed tube by evacuating the mould cavity and shot sleeve depends very heavily on the air-tightness of the parting lines between the die halves and between the die and core sliders. On the other hand, it must be kept in mind that, to be able to suck aluminium into the shot sleeve a negative pressure of only $300 \mathrm{hPa}$ is sufficient. This is equivalent to an absolute pressure in the mould cavity of around $700 \mathrm{hPa}$, which is still far removed from a technical vacuum. As a result, the mould cavity and the shot sleeve still contain $15 \mathrm{Vol}-\mathrm{OO}_{2}$, which is sufficient to form dispersed oxide films. Only a second evacuation step e.g. in the course of further movement of the plunger, would improve these conditions.

Likewise, however, components produced experimentally via shot sleeve filling from below using low pressure, have been shown to exhibit much improved material properties. This has led to a search for solutions in which the shot sleeve is filled from below independent of evacuation of the mould cavity. As a result, various comparative studies have shown that components made by filling the mould cavity from below, combined with stronger evacuation of the cavity, produced the lowest amount of fine porosity in the weld seam made using LASER welding. At the same time components manufactured this way exhibit much higher material properties, in particular elongation values, than those achieved using conventional high-pressure die-casting [7].

As before, it must be assumed that the amounts of residual oxygen in the mould cavity and shot sleeve are sufficient to cause oxidation of the surface of the molten aluminium alloy which continually breaks up during filling of the die cavity. Because of the turbulence during high-pressure die-cast-specific filling of the mould cavity, it must be assumed that the melt takes up highly dispersed, filigree oxide films and, de facto binds up the total amount of residual oxygen in the cavity in the form of ultra-fine oxide films that are then dispersed throughout the casting. The Pore-Free Die-Casting-Process, patented already in 1968, exploited exactly this situation by flooding the mould cavity with gaseous oxygen and as a result, creating a high vacuum chemically during the actual filling of the mould [8].

From the perspective of experienced die-casting experts, the problem of filling the shot sleeve from below is that the shock waves resulting from actual mould fillingshot are transmitted via the shot sleeve to the feed tube, which makes it difficult to ensure air-tightness in a process-reliable manner for a period of time. Often, design-specific reasons are presented to explain why this approach has not been able to achieve industrialisation. As a rule, the improvements in the various process steps of conventional mould 
filling mentioned at the outset here have been able to keep up with the steadily increasing demands of the user, which is why the pressure for innovation in that area has been bearable up to now.

Assuming that future applications of die-cast components will increase demands even further, the author proposes an ultimate approach to solving these problems by transferring experience from proven systems in the field of low-pressure die-casting to high-pressure die-casting. In that connection, already in the $70 \mathrm{~s}$, the author developed a rapid change system for process-capable coupling of low-pressure moulds to low-pressure die-casting furnaces (Fig. 8a). In that case the ceramic feed tube is attached outside the low pressure die-casting furnace by means of a compression seal fitting in a tool steel tube featuring a spherical geometry at the contact face to the die. This convex spherical surface at the die face is accommodated by a concave spherical surface which exhibits a slightly larger radius. As a result, this connection is self-centering within a generous tolerance range and provides a relatively robust seal, even when there are axial deviations in angle, on a sealing face that only requires a thin layer of graphite emulsion to be applied regularly. This way it is possible, during each cycle of the die-casting machine, to disconnect the feed tube from the shot sleeve mechanically by way of a short-stroke cylinder, which prevents the feed tube from suffering the shock waves produced in the system on casting. If the design details in the region of the shot sleeve unit of a die-casting machine prevent direct access with a telescopic feed tube, then this problem could be solved by means of a shortened or inclined feed tube. Also, modern insulation materials offer the possibility of employing an intermediate chamber, the net content of which is the amount of metal required for one individual casting.

In this application the previous filling opening of the shot sleeve can be fitted with a LASER measurement system to measure the level of metal and a LASER pyrometer to measure the temperature of the metal, which enable further important parameters to be used very precisely to control the process (Fig. 8b). As the shot sleeve represents a hermetically sealed system, gaseous nitrogen can be introduced into the shot sleeve as a protective medium, which is then fed into the mould during closing, thus expelling the air from the whole of the mould cavity. Taking the pressure-control which is employed as standard in low-pressure die-casting, the level of the bath is maintained just below the top of the feed tube between each casting cycle. The feed tube is then docked onto the shot sleeve by means of a short extension of the telescope immediately prior to casting (Fig. 8c).

The surfaces at the interface between the feed tube and the shot sleeve can be sprayed with a thin layer of release agent or graphite emulsion.

Figs. 8d-8g show the sequence of mould filling steps as part of the casting cycle. The docking of the feed tube to the shot sleeve takes place at the same time as the closing of the mould; the filling of the shotsleeve starts from step 8d, whereby both the level and temperature of the metal can be measured very exactly as quality determining factors by means of LASER devices, and also uses for control purposes. As soon as the set level of metal is reached, the plunger passes over the lower filling opening (Fig. 8e). As soon as this happens, the level of the metal in the feed tube can be lowered, and subsequently the feed tube itself as well, while the plunger advances slowly. As soon as the feed tube has been uncoupled, the ring-shaped sealing face can be sprayed with release agent or graphite emulsion on both sides. This is sufficient to keep these components functioning properly within two maintenance cycles (Fig. 8f). The actual shot takes place only at the moment after the feed tube has been detached from the shot sleeve (Fig. 8g). As the steps shown normally take place parallel to the movement of the plunger, the entire process takes place more or less in a time-independent manner, as with conventional filling of the shot sleeve. For maintenance and inspection purposes, the holding 


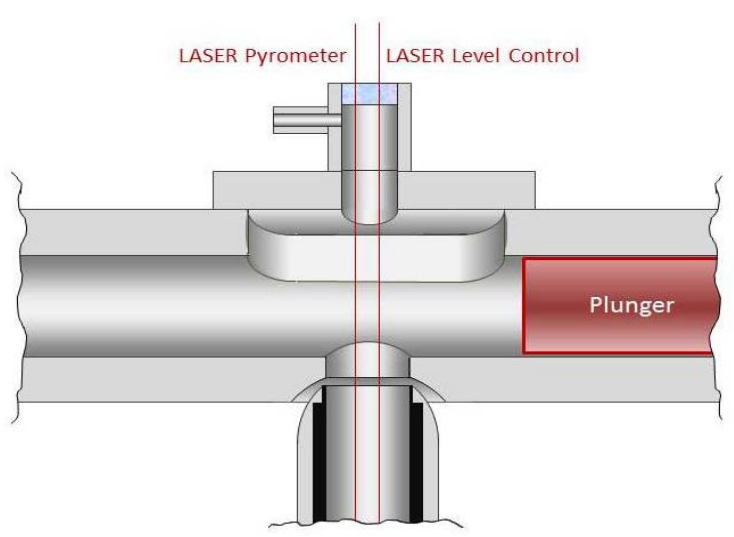

(a)

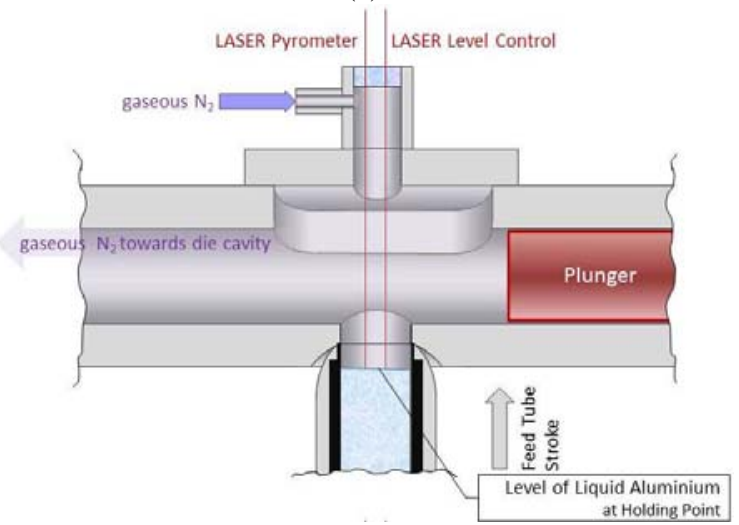

(c)

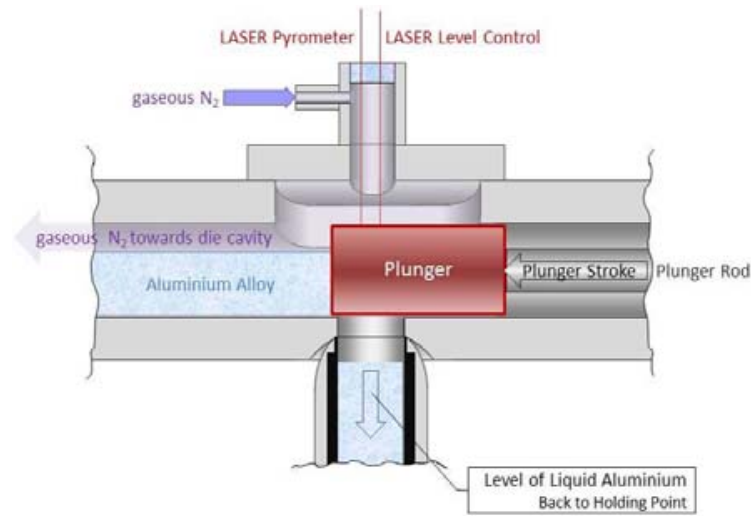

(e)

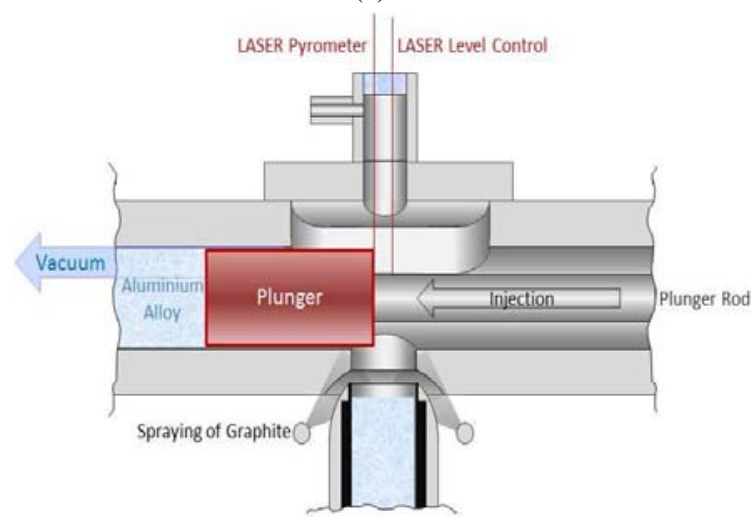

(g)

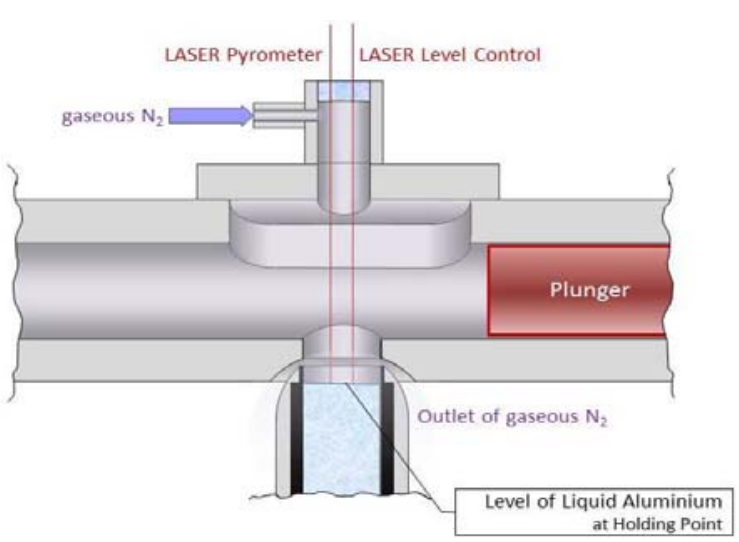

(b)

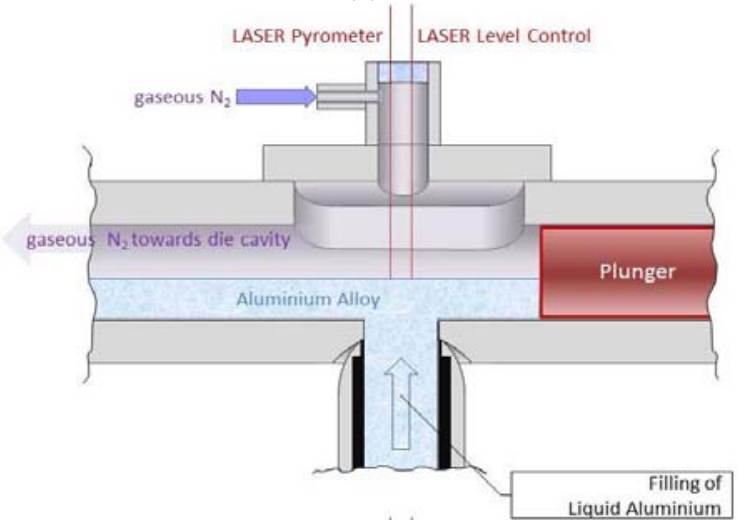

(d)

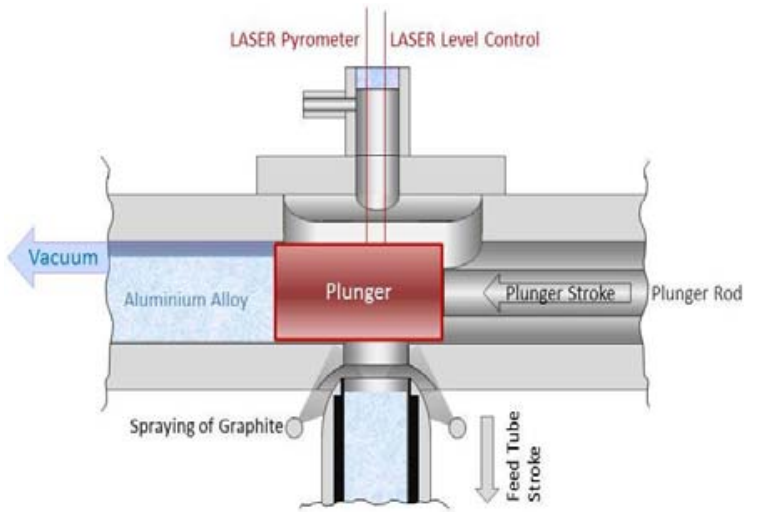

(f)

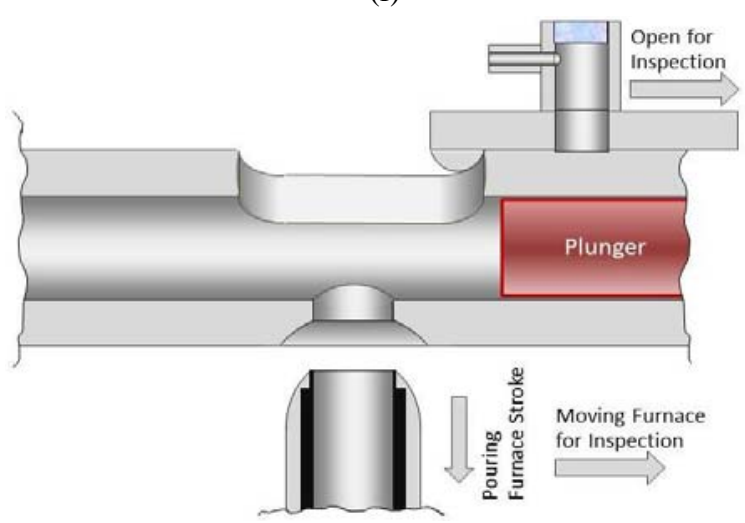

(h) 
Fig. 8 (a) Principle of a process- stable docking geometry for joining the feed tube to the shot sleeve of a die-casting machine, (b) between cycles, the shot sleeve is flooded with gaseous nitrogen and the melt maintained at the upper end of the feed tube, (c) at the cycle's start the shot sleeve is continuously flushed with nitrogen and the feed tube docked onto the shot sleeve, (d) the melt is raised out of the feed tube, resulting in a protected low-turbulence filling of the shot sleeve, (e) when the plunger passes over the filling opening of the shot sleeve, the level of melt in the feed tube is lowered again, (f) when the plunger has passed the upper opening in the shot sleeve, the vacuum is activated in the mould, (g) the plunger is actuated according to a pre-set programme to implement the actual filling of the mould cavity and (h) for maintenance and inspection purposes the shot sleeve can be opened and the holding furnace withdrawn.

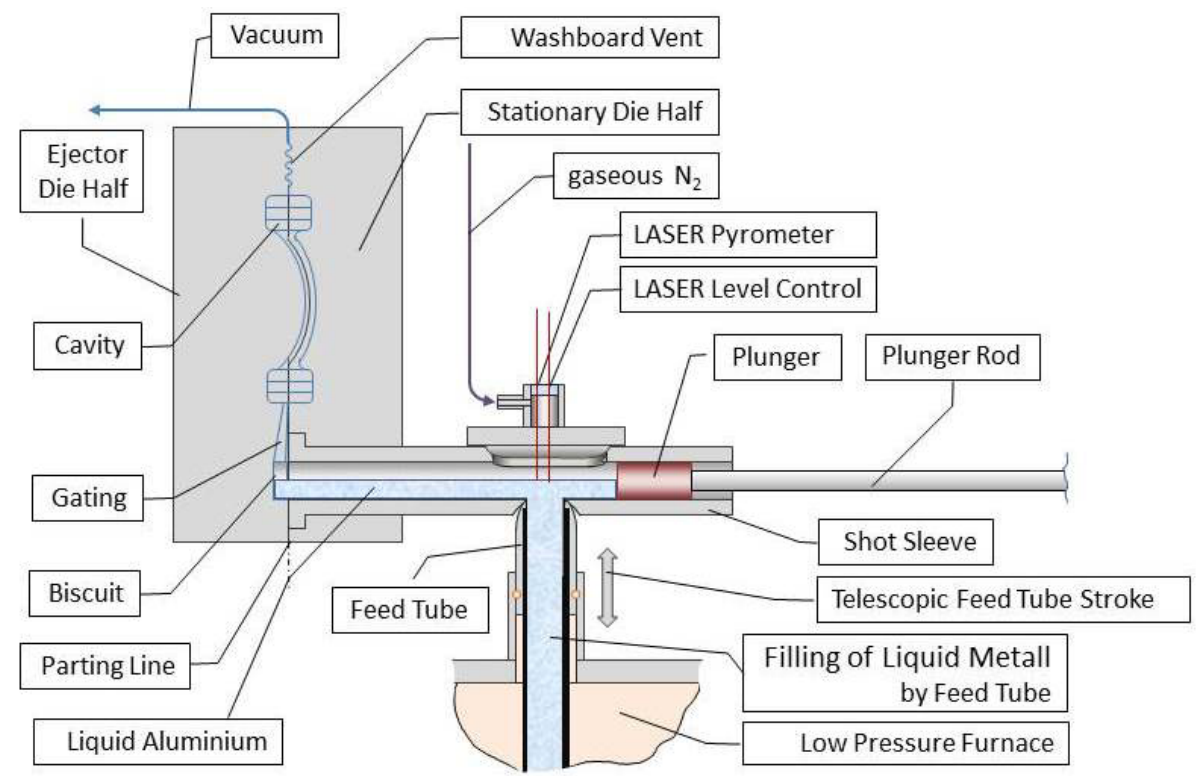

Fig. 9 Schematic representation of a high-pressure die-casting unit with mould on a cold chamber high-pressure die-casting machine for casting aluminium foundry alloys, designed for low pressure filling of the shot sleeve and nitrogen gas flushing of the cavity.

furnace can be lowered further and moved away from below the shot unit. At the same time the shot sleeve may be opened and viewed from above for inspection purposes (Fig. 8h). Fig. 9 shows the basic make up of a high-pressure die-casting unit, which is designed with maximum purity of metal in mind without extending the cycle time and without incurring additional production costs.

The author is convinced this concept is ideally suited to producing high standard components of exceptional metal quality. Combined with proven vacuum technology, die tempering and water-free spraying methods, it should ultimately be possible to achieve exceptionally high component properties. At the same time, however, the author knows that success or failure of a project never depends only on a feasible idea, no matter how attractive these may seem at first glance. Success has always been made up of countless small steps in the form of detailed, reliable solutions which make it possible to arrive at an overall solution. In that respect the author has always started with the ideal final solution in mind, and estimated the costs and advantages of the solution. Thereby, it must be accepted as realistic that, qualitative advantages only lead to technology-based, competitive advantages in the market place. Taking costs into account, it must be assumed that innovative products can at best only delay the drop in prices in the automotive supply industry, but never halt or turn that around.

The analysis has clearly shown that, in the present case, success is worth fighting for. Convinced that this will ultimately lead to a further successful step forward in aluminium foundry technology, the author will in the coming monthsintensively devote his attention to experimental work in this field with a view to realising this process innovation on an 
industrial scale.

\section{References}

[1] Campbell, J. 2013, Complete Casting Handbook, Elsevier.

[2] Brand Names of ABB Inc. Analytical Measurements, Quebec, Canada .

[3] Smetan, H. 2014. "Simply be Better is Enough- About the Simplicity of Casting." Giesserei,01.

[4] Smetan, H., Rathner, T., Plank, K.H. 2014. "New, Innovative Casting Process for Production of High Performance Components Made of Aluminum Alloys and

Source of figures

Figs.1 and 3: Benno Leinen, Viscon Werbeagentur, Eimersbergstraße 18, D-66787 Differten.

Fig. 2: John Campbell, Complete Casting Handbook 2013.

Fig. 7: Oskar Frech GmbH \& Co KG, Lortzingstraße 56, D-73614 Schorndorf.

All other figures: Herbert Smetan, SMETAN engineering GmbH, Auf der Hardt 34, D-66780 Rehlingen-Siersburg. its Application in Manufacturing.” Österreichische Giesserei Rundschau, 61.

[5] Nielsen, F. 1979. Gating and Feeding Principles. Giesserei-Verlag GmbH Düsseldorf.

[6] Cold-Chamber Vacural Technology by Oskar Frech GmbH + Co. KG Company Profile. Accessed July 2014. http://www.frech.com/produkte/kaltkammer/vacural-tech nologie.html.

[7] Kallien, L. 2008. University of Applied Sciences Aalen, Yearly Summary High Pressure Die Casting, Edition 45, Part 2: Technology, Giesserei 95, 05.

[8] Eck, S. E. and Radtke-Schrade, F. 1968. Pore-Free-Die-Casting, US-Patent No. 3,382,910. 